\title{
Diversity of reef fishes in trap fishery at Keelakarai, Gulf of Mannar, south-east coast of India
}

\author{
MOLLY VARGHESE, L. RANJITH* AND K. K. JOSHI \\ ICAR-Central Marine Fisheries Research Institute, Kochi - 682 018, Kerala, India \\ ${ }^{*}$ Tuticorin Research Centre of ICAR-Central Marine Fisheries Research Institute, Tuticorin - 628001 \\ Tamil Nadu, India \\ e-mail:mollykandathil@hotmail.com
}

\begin{abstract}
The diversity of finfishes caught in traps at Keelakarai, Gulf of Mannar was assessed quantitatively and qualitatively for a period of six years from July 2006 to June 2012. Average landing during the period was $109 \mathrm{t}$ per year with maximum of 137 t during 2008-09. Among the 98 species of reef fishes landed, Siganus canaliculatus dominated (28\%), followed by Scarus ghobban (21\%). During the first two years of the study, S. ghobban dominated over S. canaliculatus and later the trend reversed. Family-wise, maximum contribution was by Siganidae (36\%) followed by Scaridae (21\%). Seasonally, the major peak was recorded during post-monsoon of 2009. The Shannon index of diversity was maximum during 2007-08. Cluster analysis indicated the highest similarity in species composition between 2010-11 and 2011-12. SIMPER analysis identified 26 species as most significant in creating the observed pattern of similarity for $90 \%$ cut off contributions. Ellipse plot showed statistically significant deviation in fish diversity between years. Reef fish landings showed an increasing trend from 2006-07 to 2008-09, a decline afterwards and then almost steady condition prevailed during the last two years of the study which implies that there is no scope for further increase in landings by trap fishery at Keelakarai.
\end{abstract}

Keywords: Diversity, Gulf of Mannar, Keelakarai, Reef fishes, South-east India, Trap fishery

\section{Introduction}

Trap fishing is one of the indigenous methods of fishing prevalent in the Gulf of Mannar. Traps are easy to deploy, relatively less expensive to fabricate and suitable to operate in areas with rocks and coral reefs. This may be the reason for the development of an organised trap fishery at Keelakarai where such areas are available in plenty. Several ornamental fish species are also caught in traps along with food fishes. Attractive ornamental fishes collected in live condition fetch good price, thereby forming an additional income to the fisherfolk in this area. Several researchers have studied various aspects of trap fishery operated at Keelakarai, located in Gulf of Mannar. Prabhu (1954) gave an account of the perch fishery by special traps and the different methods of operation in the Gulf of Mannar and Palk Bay around Mandapam. Lal Mohan (1985) described the changing trend in the traditional trap fishery of Keelakarai and Rameswaram. Varghese et al. (2008) gave an account of trap fishing in the Gulf of Mannar and Palk Bay. Murugan and Durgekar (2008) have touched upon the seasonal abundance of coral reef associated fishes at Keelakarai while describing the status of fisheries in Tamil Nadu. Kalaiarasan et al. (2014) gave a brief account on trap fishery during 2011-12, but emphasis was given to types of traps and qualitative aspects of fishery. Kalaiarasan et al. (2015) compared the performance of three types of traps viz., experimental traditional trap, Norwegian collapsible trap and modified Norwegian collapsible trap. Murugan et al. (2014) studied the diversity, occurrence and socio-economic aspects of snappers and job fish fisheries from Gulf of Mannar region. However, there are no recent studies describing the trap fishery in the Gulf of Mannar from Keelakarai area. Hence, an attempt was made to study the species diversity and the monthly, seasonal and yearly abundance of different species in the trap fishery at Keelakarai in Gulf of Mannar.

\section{Materials and methods}

Fortnightly samplings were done to estimate the diversity of finfishes landed by traps operated at Keelakarai $\left(09^{\circ} 14^{\prime} \mathrm{N}\right.$; $\left.78^{\circ} 47^{\prime} \mathrm{E}\right)$ in Gulf of Mannar, for a period of six years from July 2006 to June 2012. Trap fishery in Keelakarai covers an area of about 1000 ha. The reef fish species in the landings were identified using FAO identification sheets (Fischer and Bianchi, 1984), Smith and Heemstra (1986) and Munro (2000). Species-wise, family-wise, month-wise, season-wise and year-wise catch data were generated and analysed using MS-Excel. The seasons considered for the study were pre- 
monsoon (July-September), monsoon (October-December), post-monsoon (January-March) and summer (April-June) as described by Rajasegar and Sendhilkumar (2009), as the study site was located on the south-east coast of India. Each year was taken as the twelve month period from July to June. Conventional diversity indices like Shannon diversity index H'( $\left.\log _{2}\right)$ (Shannon and Wiener, 1963); Margalef's richness index d (Margalef, 1958) and Pielous evenness index J' (Pielou, 1975) were applied to compare the fish diversity between years. New diversity indices have statistical support to compare the biodiversity within different years and can be derived using average taxonomic distinctness index $\Delta^{+}$; total phylogenetic diversity index sPhi+ and taxonomic diversity index $\Delta$ (Clarke and Warwick, 2001). To compare the diversity between years, dominance plot was drawn (Lambshead et al., 1983; Clarke and Warwick, 2001) by ranking the species in decreasing order of abundance. The data were fourth root transformed before analysis for diversity indices, similarity and cluster analyses. Similarity in species composition was studied by calculating the Bray-Curtis coefficient (Clarke, 1999). Similarity matrices were constructed using the Bray-Curtis similarity measure on non-standardised logarithmic transformed data. The similarity is taken as $100 \%$ when the two samples are totally similar and as 0 when the two samples are totally dissimilar. In cluster analysis, hierarchical agglomerative clustering and in the non-metric multidimensional scaling (MDS), the Bray-Curtis similarity was used to construct the map (Clarke and Warwick, 2001). SIMPER analysis was carried out to find out the contribution of each species to the observed similarity or dissimilarity between the years. To find out the deviation from normal distribution and to test the variance between samples, $\Delta+$ and $\lambda^{+}$values were used for plotting the $95 \%$ ellipse plots. All the univariate and multivariate analyses for the diversity profile were done using PRIMER (Plymouth Routines in Multivariate Ecological Research) v.6 package developed by the Plymouth Marine Laboratory, UK (Clarke and Gorley, 2001), following Khan and Lyla (2005).

\section{Results and discussion}

\section{Quantitative abundance}

A total of $654.46 \mathrm{t}$ of reef fishes were landed by traps at Keelakarai fish landing centre during the six-year period from July 2006 to June 2012, with an average landing of $109 \mathrm{t}$ per year. This yearly average was much higher than that recorded (10.45 $\left.\mathrm{t}^{\text {year }}{ }^{-1}\right)$ by Prabhu (1954) from Gulf of Mannar. Of the total landings, maximum contribution (21\%) was during 2008-09 and minimum (10\%) was during 2006-07 (Fig. 1).

The landings were found to increase from 2006-07 to 2008-09 and then showed a decreasing trend.

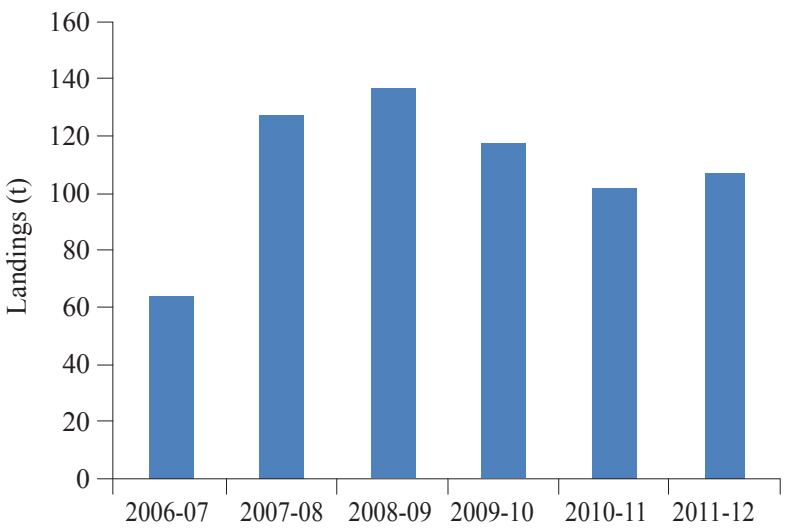

Fig. 1. Year-wise reef fish landings at Keelakarai by traps during July 2006 - June 2012

Season-wise study indicated a major peak in the fishery during post-monsoon in 2009 followed by a minor peak during monsoon of 2009 (Fig. 2). According to Kalaiarasan et al. (2014), the peak season for trap fishing at Keelakarai was from September to February based on a study for one year. Also, Murugan and Durgekar (2008) recorded monsoon season as the peak catching period. In the present study also, the seasonal peaks were observed during October-March in most of the years, which closely agrees with the above findings. As early as 1985, Lal Mohan also observed peak fishing season from December to April. A gradual increase was recorded in landings from monsoon 2006 to monsoon 2007. Then, a setback was noticed in the fishery till monsoon 2008 and it revived during the post-monsoon of 2009. During post-monsoon of 2009, the highest of $18.1 \mathrm{t}$ was landed in the month of March.

The average catch per day was found to be $349 \mathrm{~kg}$. The catch per trap showed a fluctuating trend till summer 2010 and then the catch per trap was almost steady.

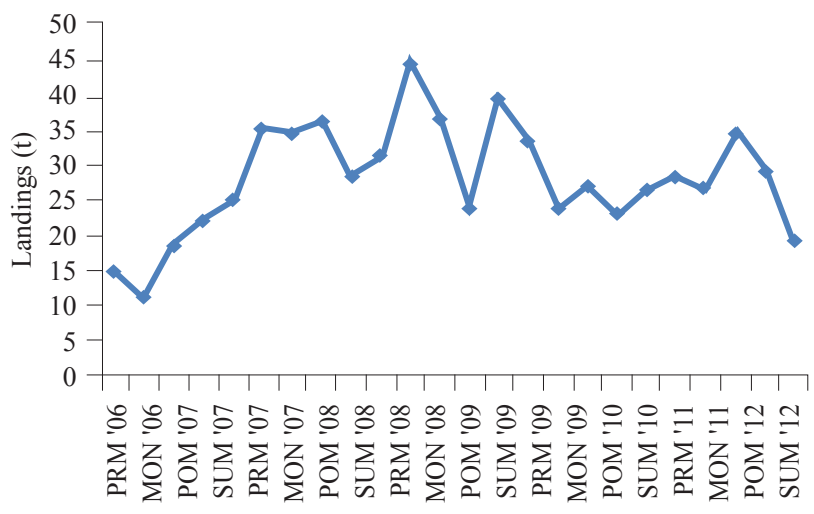

PRM: Pre-monsoon, MON: Monsoon, POM: Post-monsoon, SUM: Summer

Fig. 2. Season-wise reef fish landings at Keelakarai by traps during July 2006 - June 2012 
Average catch per trap was $1.59 \mathrm{~kg}$. Prabhu (1954) reported the catch rate per trap as $0.14 \mathrm{~kg}$ in Gulf of Mannar while Lal Mohan (1985) estimated the catch per trap as $0.48 \mathrm{~kg}$. Thus, an improvement in the catch rate was evident over the years. In case of catch per month also, there was an increase from $2844 \mathrm{~kg}$ (Lal Mohan, 1985) to $9089 \mathrm{~kg}$ during the present study. This increase in catch may be due to the different types of baits used, size and types of traps employed and change in the area of operation of the traps.

\section{Qualitative abundance}

A total of 98 species of reef fishes belonging to 27 families were recorded from the landings by traps at Keelakarai during the present study period (Table 1).

Table 1. List of reef fishes landed by traps at Keelakarai during July 2006 - June 2012

\begin{tabular}{|c|c|c|}
\hline Species & Family & Common name \\
\hline Acanthurus gahhm & Acanthuridae & Black surgeonfish \\
\hline A. lineatus & Acanthuridae & Lined surgeonfish \\
\hline A. mata & Acanthuridae & Elongate surgeonfish \\
\hline A. nigricauda & Acanthuridae & Epaulette surgeonfish \\
\hline A. triostegus & Acanthuridae & Convict surgeonfish \\
\hline A. xanthopterus & Acanthuridae & Yellowfin surgeonfish \\
\hline Zebrasoma velifer & Acanthuridae & Sailfin tang \\
\hline Balistoides viridescens & Balistidae & Titan triggerfish \\
\hline Abalistes stellaris & Balistidae & Starry triggerfish \\
\hline Caesio cuning & Caesionidae & Redbelly yellowtail fusilier \\
\hline Caranx heberi & Carangidae & Blacktip trevally \\
\hline Chaetodon decussatus & Chaetodontidae & Indian vagabond butterflyfish \\
\hline C. octofasciatus & Chaetodontidae & Eightband butterflyfish \\
\hline C.plebeius & Chaetodontidae & Blueblotch butterflyfish \\
\hline C. trifascialis & Chaetodontidae & Chevron butterflyfish \\
\hline C. vagabundus & Chaetodontidae & Vagabond butterflyfish \\
\hline C. xanthocephalus & Chaetodontidae & Yellowhead butterflyfish \\
\hline C. auriga & Chaetodontidae & Threadfin butterflyfish \\
\hline C. collare & Chaetodontidae & Redtail butterflyfish \\
\hline Heniochus acuminatus & Chaetodontidae & Pennant coralfish \\
\hline Platax teira & Ephippidae & Longfin batfish \\
\hline Neotrygon kuhlii & Dasyatidae & Blue-spotted stingray \\
\hline Plectorhinchus diagrammus & Haemulidae & Striped sweetlips \\
\hline P. pictus & Haemulidae & Trout sweetlips \\
\hline P. schotaf & Haemulidae & Minstrel sweetlips \\
\hline Diagramma picta & Haemulidae & Painted sweetlips \\
\hline Sargocentron rubrum & Holocentridae & Redcoat \\
\hline S. melanospilos & Holocentridae & Blackblotch squirrelfish \\
\hline Kyphosus cinerascens & Kyphosidae & Blue sea chub \\
\hline Cheilinus chlorourus & Labridae & Floral wrasse \\
\hline C. undulatus & Labridae & Humphead wrasse \\
\hline Halichoeres hortulanus & Labridae & Checkerboard wrasse \\
\hline H. nigrescens & Labridae & Bubblefin wrasse \\
\hline H. zeylonicus & Labridae & Goldstripe wrasse \\
\hline Hemigymnus melapterus & Labridae & Blackeye thicklip \\
\hline Thalassoma lunare & Labridae & Moon wrasse \\
\hline Psammoperca waigiensis & Latidae & Waigieu seaperch \\
\hline Lethrinus harak & Lethrinidae & Thumbprint emperor \\
\hline L. nebulosus & Lethrinidae & Spangled emperor \\
\hline
\end{tabular}

\begin{tabular}{|c|c|c|}
\hline Species & Family & Common name \\
\hline L. microdon & Lethrinidae & Smalltooth emperor \\
\hline L. miniatus & Lethrinidae & Trumpet emperor \\
\hline L. ornatus & Lethrinidae & Ornate emperor \\
\hline L. variegatus & Lethrinidae & Slender emperor \\
\hline Lutjanus argentimaculatus & Lutjanidae & Mangrove red snapper \\
\hline L. bohar & Lutjanidae & Two-spot red snapper \\
\hline L. decussatus & Lutjanidae & Checkered snapper \\
\hline L. fulviflamma & Lutjanidae & Dory snapper \\
\hline L. fulvus & Lutjanidae & Blacktail snapper \\
\hline L. gibbus & Lutjanidae & Humpback red snapper \\
\hline L. kasmira & Lutjanidae & Common bluestripe snapper \\
\hline L. lemniscatus & Lutjanidae & Yellowstreaked snapper \\
\hline L. lutjanus & Lutjanidae & Bigeye snapper \\
\hline L. quinquelineatus & Lutjanidae & Five-lined snapper \\
\hline L. rivulatus & Lutjanidae & Blubberlip snapper \\
\hline L. russellii & Lutjanidae & Russell's snapper \\
\hline L. vitta & Lutjanidae & Brownstripe red snapper \\
\hline Parupeneus barberinus & Mullidae & Dash-and-dot goatfish \\
\hline P. heptacanthus & Mullidae & Cinnabar goatfish \\
\hline P. indicus & Mullidae & Indian goatfish \\
\hline Upeneus tragula & Mullidae & Freckled goatfish \\
\hline Gymnothorax favagineus & Muraenidae & Laced moray \\
\hline G. punctatus & Muraenidae & Red Sea whitespotted moray \\
\hline Scolopsis bimaculata & Nemipteridae & Thumbprint monocle bream \\
\hline Lactoria cornuta & Ostraciidae & Longhorn cowfish \\
\hline Ostracion cubicus & Ostraciidae & Yellow boxfish \\
\hline Pempheris molucca & Pempheridae & Moluccan sweeper \\
\hline Pomacanthus semicirculatus & Pomacanthidae & Semicircle angelfish \\
\hline P. annularis & Pomacanthidae & Bluering angelfish \\
\hline Abudefduf bengalensis & Pomacentridae & Bengal sergeant \\
\hline A. septemfasciatus & Pomacentridae & Banded sergeant \\
\hline A. vaigiensis & Pomacentridae & Indo-Pacific sergeant \\
\hline Neoglyphidodon melas & Pomacentridae & Bowtie damselfish \\
\hline Bolbometopon muricatum & Scaridae & Green humphead parrotfish \\
\hline Scarus ghobban & Scaridae & Blue-barred parrotfish \\
\hline S. psittacus & Scaridae & Common parrotfish \\
\hline Chlorurus sordidus & Scaridae & Daisy parrotfish \\
\hline Pterois russelli & Scorpaenidae & Plaintai turkeyfish \\
\hline P. volitans & Scorpaenidae & Red lionfish \\
\hline Cephalopholis argus & Serranidae & Peacock hind \\
\hline C. boenak & Serranidae & Chocolate hind \\
\hline C. formosa & Serranidae & Bluelined hind \\
\hline Epinephelus bleekeri & Serranidae & Duskytail grouper \\
\hline E. chlorostigma & Serranidae & Brownspotted grouper \\
\hline E. coeruleopunctatus & Serranidae & Whitespotted grouper \\
\hline E. longispinis & Serranidae & Longspine grouper \\
\hline E. diacanthus & Serranidae & Spinycheek grouper \\
\hline E. flavocaeruleus & Serranidae & Blue-and-yellow grouper \\
\hline E. malabaricus & Serranidae & Malabar grouper \\
\hline E. merra & Serranidae & Honeycomb grouper \\
\hline E. polyphekadion & Serranidae & Camouflage grouper \\
\hline E. tauvina & Serranidae & Greasy grouper \\
\hline Siganus canaliculatus & Siganidae & White-spotted spinefoot \\
\hline S.javus & Siganidae & Streaked spinefoot \\
\hline S. lineatus & Siganidae & Golden-lined spinefoot \\
\hline S. spinus & Siganidae & Little spinefoot \\
\hline Arothron hispidus & Tetraodontidae & White-spotted puffer \\
\hline A. stellatus & Tetraodontidae & Stellate puffer \\
\hline Zanclus cornutus & Zanclidae & Moorish idol \\
\hline
\end{tabular}


Kalaiarasan et al. (2014) observed fishes of 24 families in landings from traps at Keelakarai and the higher number of families recorded during the present study may be due to the long duration of the study period. The family-wise distribution of landings is given in Fig. 3 (families forming less than $1 \%$ of landings are not included).

Family-wise estimates showed that Siganidae formed maximum (36\%) of the landings by traps during the period under study, followed by Scaridae (21\%), Lethrinidae (11\%), Serranidae $(8 \%)$ and Mullidae (7\%).

Among the species landed, Cheilinus undulatus categorised as 'Endangered' in the IUCN Red List, was also observed. Ninety-eight species of reef fishes were landed during the present study, whereas 92 species were

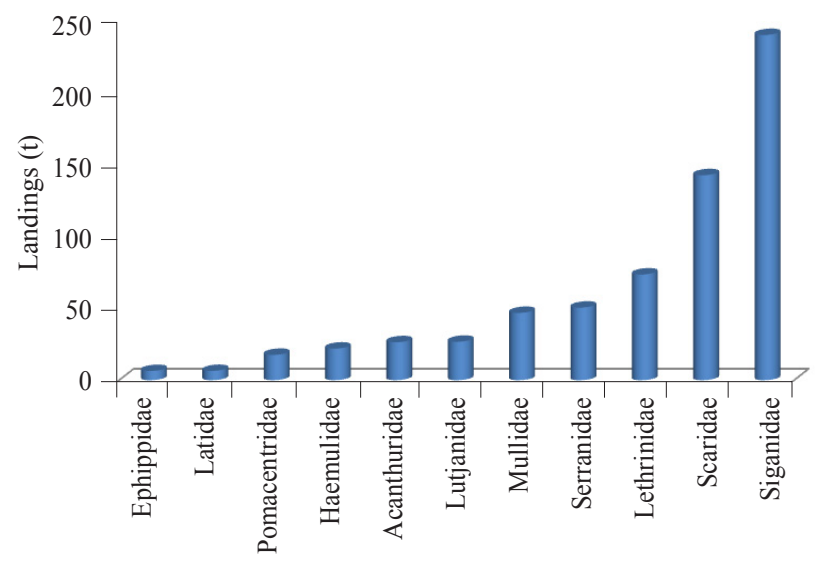

Fig. 3. Family-wise reef fish landings at Keelakarai fish landing centre by traps during July 2006 - June 2012

recorded by Murugan and Durgekar (2008) from traps employed in Keelakarai. Species composition of fish landings at Keelakarai by traps is depicted in Fig. 4.

Siganus canaliculatus contributed maximum and formed $28 \%$ of the landings. This was followed by Scarus ghobban (21\%). Lethrinus nebulosus and Siganus javus formed $8 \%$ each, Parupeneus indicus contributed $7 \%$ and rest of the species formed only less than $5 \%$ each. As early as 1954 , Prabhu observed that L. nebulosus and S. ghobban formed 56.8 and $25.9 \%$ of the trap landings in Gulf of Mannar whereas Lal Mohan (1985) noticed that the trap fishery in Gulf of Mannar depended mainly on L. nebulosus, S. canaliculatus and S. ghobban, which formed 45, 26.2 and 10\% respectively. The above studies indicate that there exists a temporal shift in the abundance of species in trap landings in Gulf of Mannar. Season-wise abundance of dominant species recorded during the present study is indicated in Fig. 5.

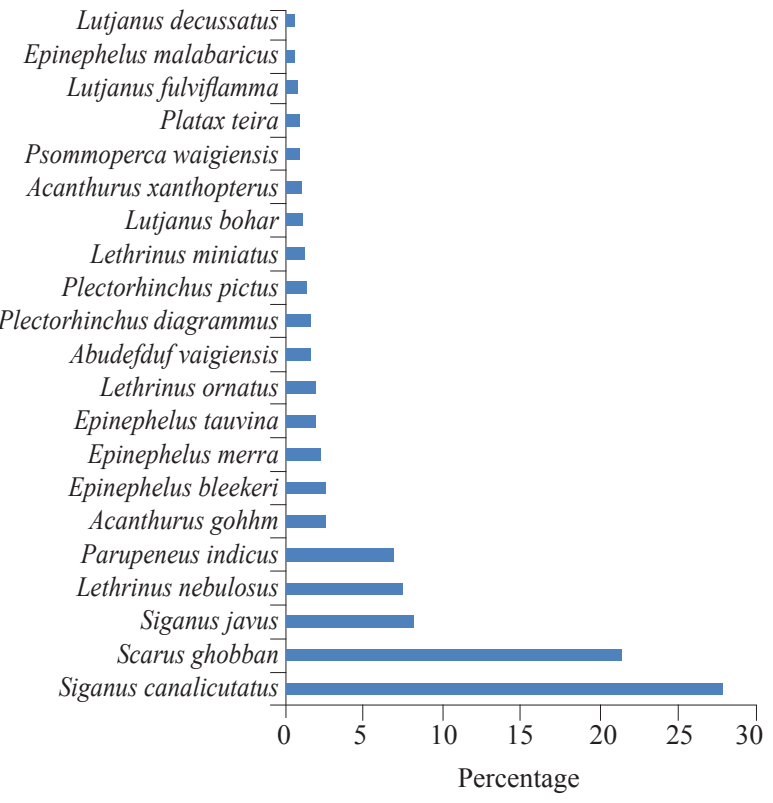

Fig. 4. Species-wise dominance (\%) among total reef fishes landed at Keelakarai by traps during July 2006 - June 2012

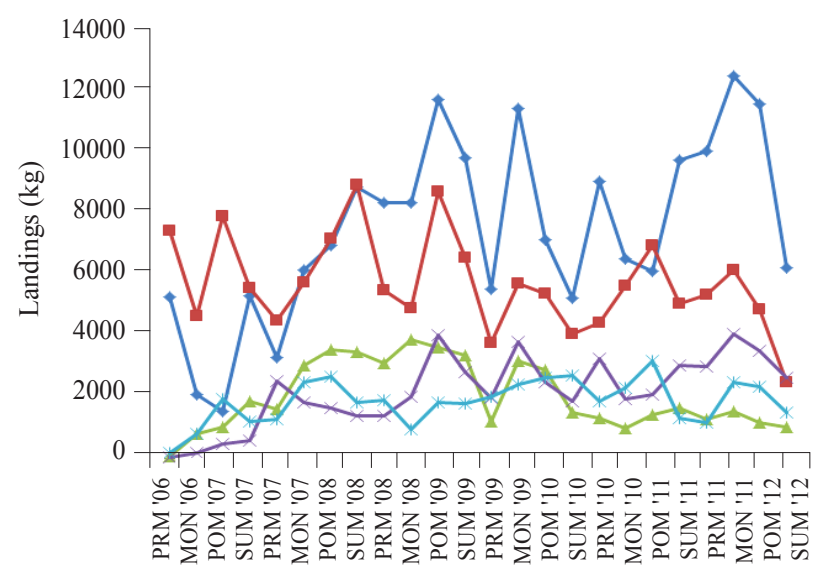

PRM: Pre-monsoon, MON: Monsoon, POM: Post-monsoon, SUM: Summer

$\rightarrow$ Siganus canaliculatus, $\rightarrow$ Scarus ghobban,
$\rightarrow$ Siganus javus, $\rightarrow$ Lethrinus nebulosus,

Fig. 5. Season-wise landings of dominant species by traps at Keelakarai during July 2006 - June 2012.

The most dominant species, S. canaliculatus showed a fluctuating trend and reached the major peak in the monsoon of 2011. In general, S. canaliculatus and S. javus were found to increase while $S$. ghobban and L. nebulosus showed a decreasing trend during the period of study. There was a clear shift in the abundance of S. ghobban and S. canaliculatus. Upto summer season of 2008, S. ghobban dominated over $S$. canaliculatus but afterwards the trend was reversed. The size of $S$. ghobban was also found to decrease substantially after the initial period. This decline in the abundance of S. ghobban may be due to overexploitation, and increase 
in the abundance of $S$. canaliculatus may be attributed to the use of more of shrimp head, shrimp peelings and jelly fishes as bait in the trap.

\section{Biodiversity}

A community diversity analysis to discern the species status for the different years was carried out (Table 2). Margalef's richness (d) and Fisher's alpha showed highest values in 2006-07 (4.16 and 4.82 respectively) whereas lowest were observed during 2011-12 (2.26 and 2.50 respectively). Another major component of diversity i.e., Pielou's evenness or equitability J' was the highest in 2007-08 (0.65) and the lowest was during 2006-07 (0.50). The Simpson index pattern (Fig. 6). The curve for the year 2007-08, which lies on the lower side, extends further and rises slowly due to presence of more number of species. As the percentage contribution of each species is added, the curve extends horizontally (species number is evident from the $x$-axis), before reaching the cumulative $100 \%$. In the typical undisturbed ecosystem, the K-dominance curve is S-shaped and Fig. 6 clearly shows curve wih a gentle slope and medium starting point indicating medium diversity.

The Bray-Curtis similarity coefficient (Table 3) is extensively used to find out the degree of relationship in species composition and abundance between samples

Table 2. Diversity indices of fishes during different years

\begin{tabular}{|c|c|c|c|c|c|c|c|c|c|c|c|}
\hline Year & $\mathrm{S}$ & $\mathrm{N}$ & $\mathrm{d}$ & $\mathrm{J}^{\prime}$ & Fisher & $H^{\prime}\left(\log _{2}\right)$ & 1-Lambda' & Delta & Delta+ & Lambda + & sPhi+ \\
\hline 2006-07 & 55 & 434928 & 4.16 & 0.50 & 4.82 & 2.87 & 0.76 & 32.20 & 43.85 & 72.82 & 1485.71 \\
\hline 2007-08 & 56 & 959819 & 3.99 & 0.65 & 4.57 & 3.76 & 0.87 & 35.28 & 43.96 & 106.79 & 1600.00 \\
\hline 2008-09 & 37 & 1086684 & 2.59 & 0.62 & 2.88 & 3.23 & 0.80 & 31.70 & 41.01 & 82.40 & 1028.57 \\
\hline $2009-10$ & 44 & 908738 & 3.13 & 0.62 & 3.53 & 3.36 & 0.82 & 32.56 & 42.77 & 80.68 & 1285.71 \\
\hline $2010-11$ & 34 & 818010 & 2.42 & 0.57 & 2.69 & 2.89 & 0.76 & 29.10 & 40.49 & 60.96 & 928.57 \\
\hline 2011-12 & 32 & 900577 & 2.26 & 0.52 & 2.50 & 2.58 & 0.70 & 25.28 & 40.78 & 54.13 & 928.57 \\
\hline
\end{tabular}

(1-lambda) provided information on dominance of species and it was found to be high in 2007-08 (0.87) and low in 2011-12 (0.70). Shannon index of diversity H' $\left(\log _{2}\right)$ which is a more realistic estimate of biodiversity was found to be the highest in 2007-08 (3.76) and the lowest was found to be observed in 2011-12 (2.58). In the present investigation, the Shannon indices of diversity were medium varying from 2.58 to 3.76 . Seasonally, the maximum diversity ( $\mathrm{H}^{\prime}$ ) was recorded during monsoon of 2007 and diversity was found to be higher during monsoon or post-monsoon seasons in most of the years during the study period.

The conventional indices can only be used with quantitative data as they are much influenced by the sampling effort and evenness property. The newly introduced biodiversity indices have additional statistical framework for comparison of one sample with another. The taxonomic diversity index was more in 2007-08 (35.28) and less in 2011-12 (25.28). The total phylogenetic diversity index was also more in 2007-08 (1600) and it was less in 2010-11 and 2011-12 (928.57). The average taxonomic distinctness index was more in 2007-08 (43.96) and less in 2010-11 (40.49). The results revealed that the biodiversity rich year of 2007-08, had more stability and less variation than other periods, where the variation in taxonomic diversity index was comparatively low.

The dominance plot or K- dominance curve was constructed on the data sets to find out the biodiversity

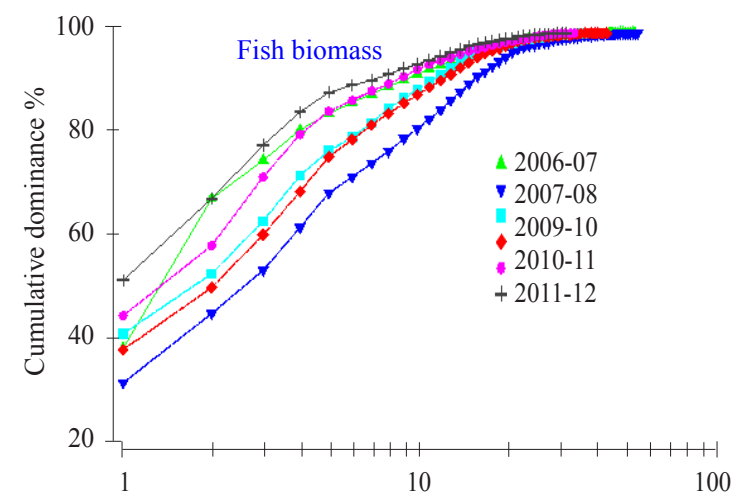

Fig. 6. Dominance plot for fishes landed by traps at Keelakarai during July 2006 - June 2012

Table 3. Bray-Curtis similarity for fishes collected from different years

\begin{tabular}{lllllll}
\hline Year & $2006-07$ & $2007-08$ & $2008-09$ & $2009-10$ & $2010-11$ & $2011-12$ \\
\hline $2006-07$ & & & & & & \\
$2007-08$ & 66.62 & & & & & \\
$2008-09$ & 59.08 & 75.26 & & & & \\
$2009-10$ & 61.20 & 71.42 & 78.26 & & & \\
$2010-11$ & 60.01 & 69.27 & 79.54 & 80.75 & & \\
$2011-12$ & 56.95 & 67.71 & 78.25 & 76.33 & 90.29 & \\
\hline
\end{tabular}

collected from various places. This coefficient varies from 0 to $100 \%$, with the ends of the range representing the extreme possibilities. The similarity is $100 \%$ if the two samples are totally similar and it is 0 if the two samples are totally dissimilar. The highest similarity was found 
between the year 2010-11 and 2011-12 with 90.29\% similarity among themselves and low similarity was found between 2006-07 and 2011-12 (56.95\%).

Cluster analysis (dendrogram) revealed grouping of years with respect to species composition in the area (Fig. 7). The year 2010-11 and 2011-12 formed a group with the maximum similarity percentage of 90 .

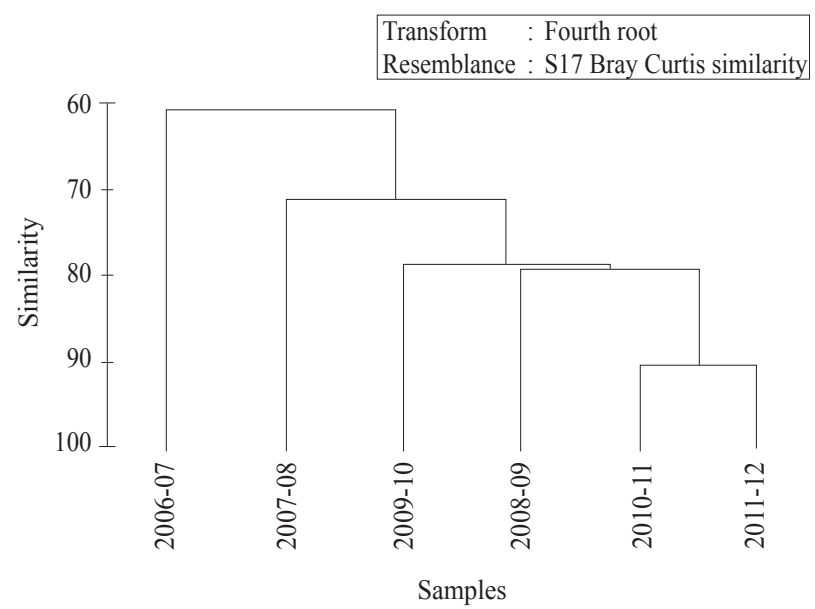

Fig. 7. Dendrogram of fishes recorded in various years

In the MDS bubble plot, the abundance of species and dissimilarity between the years were superimposed as circles of different sizes. The bubble plots give the abundance of discriminating species which is evident from the size of the bubble, greater the bubble size, higher the abundance of the fish species. Bubble plot of $S$. canaliculatus, the most dominant species is given in Fig. 8.

The results of SIMPER analysis are given in Table 4. The term 'average abundance' represents the average abundance (by numbers) in each year. The 'average contribution' represents the average contribution of each year to the average dissimilarity between the years.

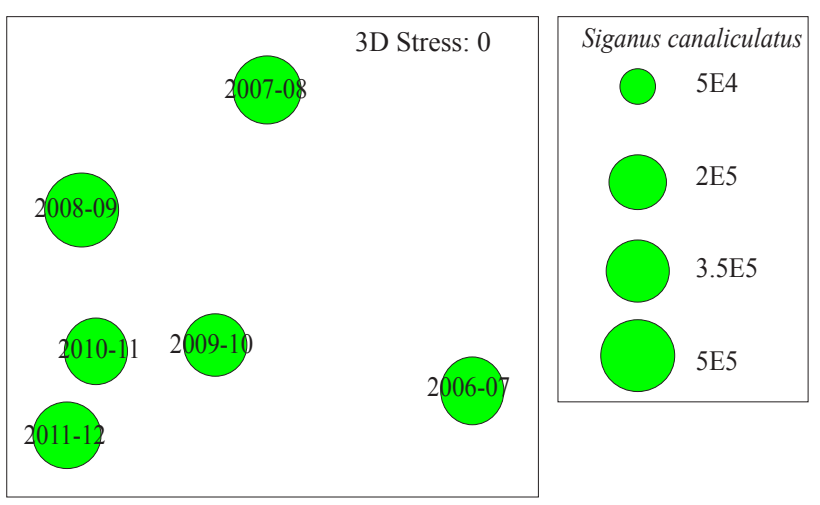

Fig. 8. Bubble plot for Siganus canaliculatus
The ratio indicates average contribution to the standard deviation between the years. The higher-contributing species was taken wherein the species contributing a small amount to the similarity and dissimilarity are dropped. The cut off for low contributions given was $90 \%$ and rare species after the cumulative percentage cut off point are ignored.

Twenty six higher-contributing species (Table 4) were taken out of ninetyeight species for the $90 \%$ cut off contributions. The identified 26 species were the most important in creating the observed pattern of similarity. The average similarity between group members, based on the Bray-Curtis similarity measure, is $71.40 \%$. S. canaliculatus contributes about $23.82 \%$ (with average similarity of $6.61 \%$ ) to the total similarity followed by S. ghobban contributing about $18.46 \%$ (with average similarity of $5.28 \%$ ) and $S$. javus contributing about $17.12 \%$ (with average similarity of $4.54 \%$ ).

The fitted $95 \%$ probability contours of average taxonomic distinctness (delta + ) and variation in taxonomic distinctness (lambda + ), showing statistically significant deviation in fish diversity between the years are depicted in Fig. 9. In the ellipse plot of the average taxonomic distinctness and variation in taxonomic distinctness, the values show statistically significant departure from the ellipse for all the observation years.

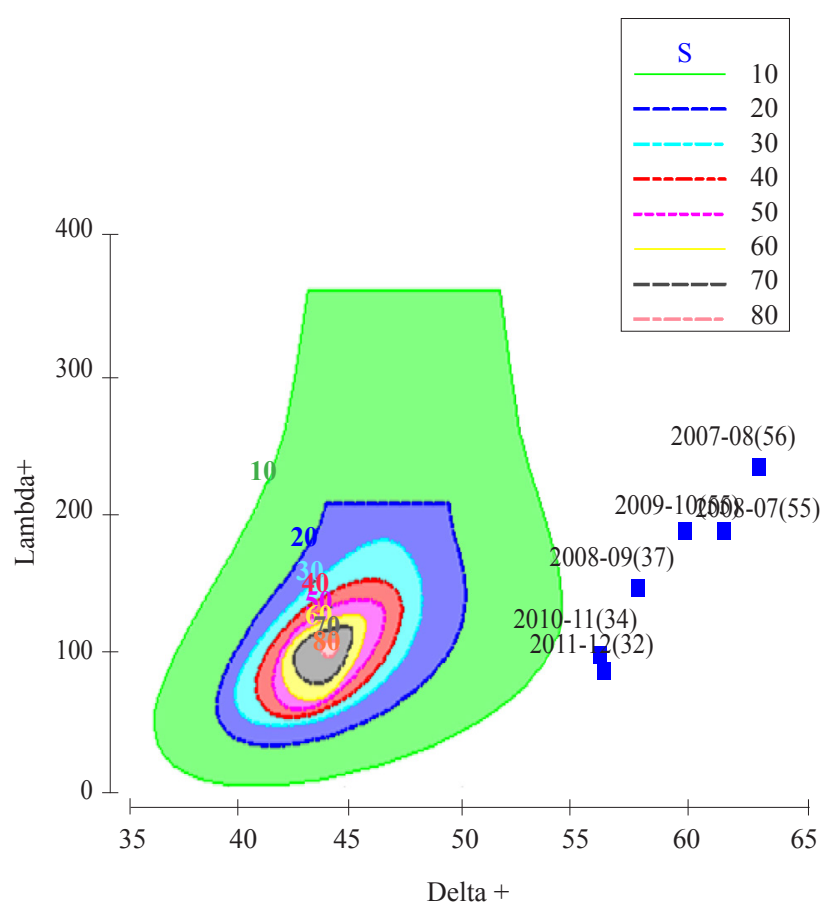

Fig. 9. The $95 \%$ probability contours of average taxonomic distinctness $($ delta +$)$ and variation in taxonomic distinctness (lambda + ), showing statistically significant deviation in fish diversity between the years 
Table 4. SIMPER analysis of dissimilarity between years

\begin{tabular}{|c|c|c|c|c|c|}
\hline Species & Average abundance $(\%)$ & Average similarity (\%) & Ratio & Average contribution (\%) & Cumulative contribution ( $\%)$ \\
\hline Siganus canaliculatus & 23.82 & 6.61 & 7.49 & 9.26 & 9.26 \\
\hline Scarus ghobban & 18.46 & 5.28 & 10.6 & 7.4 & 16.65 \\
\hline Siganus javus & 17.12 & 4.54 & 4.24 & 6.35 & 23 \\
\hline Parupeneus indicus & 15.6 & 4.37 & 9.29 & 6.12 & 29.12 \\
\hline Lethrinus nebulosus & 15.18 & 4.07 & 12.26 & 5.7 & 34.82 \\
\hline Abudefduf vaigiensis & 11.35 & 3.02 & 7.93 & 4.23 & 39.05 \\
\hline Lethrinus ornatus & 11.06 & 2.92 & 7.51 & 4.09 & 43.14 \\
\hline Acanthurus gahhm & 10.96 & 2.79 & 7.01 & 3.9 & 47.05 \\
\hline Lethrinus miniatus & 9.74 & 2.57 & 4.52 & 3.61 & 50.65 \\
\hline Epinephelus merra & 9.57 & 2.44 & 6.73 & 3.42 & 54.07 \\
\hline Psammoperca waigiensis & 9.22 & 2.25 & 5.67 & 3.16 & 57.23 \\
\hline Epinephelus tauvina & 8 & 2.25 & 10.99 & 3.15 & 60.38 \\
\hline Plectorhinchus pictus & 7.99 & 2.16 & 5.91 & 3.02 & 63.4 \\
\hline Abudefduf septemfasciatus & 8.43 & 2.07 & 5.66 & 2.9 & 66.3 \\
\hline Lutjanus fulviflamma & 8.55 & 2.02 & 4.89 & 2.84 & 69.14 \\
\hline Plectorhinchus diagrammus & 7.93 & 1.96 & 3.39 & 2.75 & 71.88 \\
\hline Epinephelus bleekeri & 9.29 & 1.95 & 1.36 & 2.73 & 74.61 \\
\hline Lutjanus bohar & 8 & 1.71 & 1.35 & 2.4 & 77.01 \\
\hline Platax teira & 7.13 & 1.41 & 1.06 & 1.97 & 78.98 \\
\hline Abudefduf bengalensis & 7.68 & 1.37 & 1.32 & 1.92 & 80.89 \\
\hline Caesio cuning & 5.77 & 1.36 & 3.17 & 1.91 & 82.8 \\
\hline Acanthurus xanthopterus & 6.72 & 1.17 & 1.29 & 1.64 & 84.44 \\
\hline Plectorhinchus schotaf & 5.06 & 1.17 & 1.34 & 1.64 & 86.08 \\
\hline Acanthurus mata & 4.84 & 1 & 1.27 & 1.41 & 87.49 \\
\hline Lutjanus lutjanus & 5.11 & 1 & 1.3 & 1.39 & 88.88 \\
\hline Epinephelus malabaricus & 4.87 & 0.94 & 1.11 & 1.31 & 90.2 \\
\hline
\end{tabular}

The present investigation indicated that the reef fish landings by traps at Keelakarai increased from 2006-07 to 2008-09 and then showed a decline and the landings were almost steady during 2010-11 and 2011-12. Highest similarity was found between 2010-11 and 2011-12 $(90.29 \%)$. The catch per trap was also found to be steady after 2010. This indicates that the exploitation level of resources in the trap fishery at Keelakarai might have attained its maximum level.

\section{Acknowledgements}

The authors are grateful to the Director, ICAR-CMFRI, Kochi; Dr. Mary K. Manisseri, Dr. Rani Mary George and to Dr. G. Gopakumar for providing facilities and encouragement. They are also thankful to Shri. C. Kasinathan, Shri. A. Gandhi, Shri. V. J. Thomas, Smt. P. M. Geetha, Shri. K. M. Sreekumar and Shri. M. Seeni for the help rendered during the study.

\section{References}

Clarke, K. R. 1999. Nonmetric multivariate analysis in community level ecotoxicology. Environ. Toxicol. Chem., 18(2): 118-127.

Clarke, K. R. and Gorley, R. N. 2001. PRIMER v6: User manual, PRIMER-E, Plymouth, UK, $91 \mathrm{pp}$.
Clarke, K. R. and Warwick, R. M. 2001. Changes in marine communities: An approach to statistical analysis and interpretation, PRIMER - E, Plymouth, $112 \mathrm{pp}$.

Fischer, W. and Bianchi, G. 1984. FAO species identification sheets for fishery purposes. Western Indian Ocean (Fishing Area 51), vol. 4. FAO, UN, Rome.

Kalaiarasan, M., Neethiselvan, N., Sundaramoorthy, B., Shanmugam, S. A. and Xavier, P. Rayan 2015. Modified Norwegian trap for marine ornamental and food fishes off south-east coast of India. Fish. Technol., 52: 71-79.

Kalaiarasan, M., Neethiselvan, N., Sundaramoorthy, B., Shanmugam, S. A., Xavier, P. Rayan and Velmurugan, R. 2014. Studies on the traditional trap fishery of Keelakarai coast. J. Exp. Zool. India, 17(1): 265-271.

Khan, S. A., Raffi, S. M. and Lyla, P. S. 2005. Brachyuran crab diversity in natural (Pitchavaram) and artificially developed mangroves (Vellar Estuary). Curr. Sci., 88(8): 1316-1324.

Lal Mohan, R. S. 1985. A note on the changing catch trend in the traditional trap-fishery of Keelakarai and Rameswaram. Indian J. Fish., 32(3): 387-391.

Lambshead, P. J. D., Platt, H. M. and Shaw, K. M. 1983. The detection of differences among assemblages of marine benthic species based on an assessment of dominance and diversity. J. Nat. Hist., 17: 859-874. 
Margalef, R. 1958. Information theory in ecology. General Systematics, 3: 36-71.

Munro, I. S. R. 2000. The marine and freshwater fishes of Ceylon, Narendra Publishing House, New Delhi, India, 352 pp.

Murugan, A. and Durgekar, R. 2008. Beyond the Tsunami, Status of fisheries in Tamil Nadu, India: A Snapshot of present and long-term trends. UNDP/UNTRS, Chennai and ATREE, Bangalore, India, 75 pp.

Murugan, A., Vinod, K., Saravana, K. R., Anbalagan, Y., Saravanan, R., Sanaye, S., Mojjada, S. K., Rajagopal, S. and Balasubramanian, T. 2014. Diversity, occurrence and socio-economic aspects of snappers and job fish (Family: Lutjanidae) fisheries from Gulf of Mannar region, south-east coast of India. J. Geo-marine Sci., 43(4): 618-633.

Pielou, E. C. 1975. Ecological diversity. Wiley and Sons, New York, viii +165 pp.
Prabhu, M. S. 1954. The perch fishery by special traps in the area around Mandapam in the Gulf of Mannar and Palk Bay. Indian J. Fish., 1(1): 94-129.

Rajasegar, M. and Sendhilkumar, R. 2009. Finfish resources of Karaikal, south-east coast of India. World J. Fish Mar. Sci., 1(4): 330-332

Shannon, C. E. and Wiener, W. 1963. The mathematical theory of communication. University of Juionis Press, Urbana. $117 \mathrm{pp}$.

Smith, M. M. and Heemstra, P. C. 1986. Smith's sea fishes. Springer-Verlag, Berlin, 1048 pp.

Varghese Molly, Kasinathan, C. and Gandhi, A. 2008. Trap fishing in the Gulf of Mannar and Palk Bay. Mar. Fish. Infor. Serv. T\&E Ser., 197: 7-8. 